MURIEL LAURENT

Profesora asociada del Departamento de Historia de la Universidad de los Andes y además directora de la revista Historia Crítica de la misma institución. Su principal línea de investigación se refiere al tema del contrabando en Colombia en el siglo xIx. Sus más recientes publicaciones son: "Le phénomène de la contrebande en Colombie au xixème siècle", Revue Canadienne d'Études Latino-Américaines et des Caraẗbes-Revista Canadiense de Estudios Latinoamericanos y del Caribe (RCELAC), vol. 30, núm. 59, enero de 2005; "Aproximaciones teóricas al contrabando: el caso del oro antioqueño durante la primera mitad del siglo XIX", con Antonio Ochoa y Diana Urbano, Revista de Lstudios Sociales (RES), Facultad de Ciencias Sociales de la Universidad de los Andes, núm. 17, febrero de 2004, Bogotá, pp. 69-78; "Nueva Francia y Nueva Granada frente al contrabando: reflexiones sobre el comercio ilícito en el contexto colonial", Historia Crítica, Departamento de Historia de la Universidad de los Andes, núm. 5, enero-junio de 2003, Bogotá, pp. 137-163. 
EL CONTRABANDO EN COLOMBIA DURANTE

EL SIGLO XIX (1821-1886): FUENTES DOCUMENTALES Y ASPECTOS METODOLÓGICOS PARA SU ESTUDIO

\author{
Muriel Laurent
}

$\mathrm{E}$

los últimos cinco años, el tema del contrabando en la Colombia decimonónica ha llamado poderosamente mi atención. ${ }^{1}$ Los motivos subyacentes a la elección de este tema radican, por una parte, en un interés personal, aspecto que no suele faltar en la elección de un objeto de estudio por parte del historiador, y, además, en la voluntad de indagar en un campo poco abordado por la historiografía colombiana. De hecho, como se detallará más adelante, si bien el contrabando en el siglo XIX es una realidad advertida por la mayoría de los historiadores nacionales y extranjeros de dicho siglo, particularmente en relación con la historia económica del país, este tema no ha recibido hasta el momento un tratamiento específico.

Adicionalmente, la premisa según la cual la existencia del contrabando durante el periodo colonial ${ }^{2}$ tenía que ver con el sistema mercantilista español, generó una inquietud respecto a su permanencia después del

${ }^{1}$ Agradezco a COLCIENcias (entidad pública colombiana dedicada al apoyo de las Ciencias) que, a raíz de la convocatoria Programa Nacional de Ciencias Sociales y Humanas-dimensión ética, de 1999, cofinanció mi investigación (El libro que recoge los resultados de este estudio está en preparación). Para la elaboración definitiva del presente artículo, agradezco a los
evaluadores anónimos cuyos valiosos comentarios he considerado pertinente incluir para completar mi escrito.

${ }^{2}$ Respecto al contrabando colonial y para el caso de Nueva Granada, se pueden consultar los siguientes trabajos: Arauz, Contrabando, 1984; Barrera, Mestizaje, 2000; Grahn, Political,
1997; Múnera, "Ilegalidad", 1994; Múnera, Fracaso, 1998; Polo, "Contrabando", 2000, y 1997; Múnera, "Ilegalidad", 1994; Múnera, Fracaso, 1998; Polo, "Contrabando", 2000, y Vidal, Cartagena, 2002

AmÉrica latina en la Historia Económica número 24, julio-diciembre de 2005 [ 155 ] 
establecimiento de la república e incluso hasta la actualidad, ${ }^{3}$ puesto que la independencia, con el paso a nuevas reglas económicas, hubiera tenido que poner fin a esta práctica ilícita. En consecuencia, las preguntas que orientaron el trabajo radicaban en analizar el por qué y el cómo de la persistencia del contrabando una vez obtenida la independencia definitiva en 1821. En esta medida, la temporalidad elegida es larga puesto que el estudio se concentra en el siglo XIX posindependencia, concretamente de 1821 a 1886 , última fecha que fue elegida por motivos que se señalarán más adelante. Asimismo, el espacio geográfico es amplio ya que toma en cuenta el territorio de la Colombia actual, con el fin de abarcar las distintas fronteras del país. ${ }^{4}$

Para responder a los objetivos de la investigación, un primer paso consistía en determinar las características del comercio ilícito decimonónico: los productos que se contrabandeaban, las rutas por las cuales se conducían y quiénes lo practicaban. Además, había que resolver inquietudes acerca de las opiniones que circulaban en torno a su existencia, las medidas que se tomaban para evitarlo, las autoridades administrativas encargadas de este control y los problemas a los que se enfrentaban dichas autoridades a la hora de reprimirlo. Se consideró paso obligado averi-

${ }^{3}$ En cuanto al contrabando en este inicio del siglo xxi (licores, cigarrillos, perfumes, calzado, electrodomésticos, gasolina, etc.) remitirse a la prensa cotidiana y semanal, por ejemplo: Efraín Pachón, "La danza del serrucho en la Aduana. Con el remezón en la costa, el gobierno le asestó dos golpes al contrabando", El Espectador, 3 de noviembre de 2002, p. 17; "Quién es Lopesierra, el Hombre Marlboro", Cambio, núm. 532, 8 de septiembre de 2003, p. 18; "Sin etiqueta", Cambio, num. 491,18 de noviembre de 2002 , pp. $80-81$; "Gobierno emite decreto para frenar con abando de gasona", Semana, núm. 1065, 3 de octubre de 2002; así "DIAN retiene contrabando por \$ 710324855 en Medellin", 28 de febrero de 2003; "En Sanandresitos de Barranquilla y Cali DIAN aprehendió contrabando de licores extranjeros", 28 de febrero de 2003; "Millonarias aprehensiones de contrabando en todo el país (Buenaventura, Medellin, Bogotá y Cartagena)", 24 de octubre de 2002. Los Sanandresitos son locales comertienen su nombre de la isla colombiana de San Andrés en el mar Caribe desde donde se desarrolló un importante flujo ilegal.

${ }^{4}$ Durante el siglo XIX, el territorio de la actual Colombia cambió en varias ocasiones de nombre y de organización política, y aunque continuó siendo republicana, también evolucionó. De. 1821 a 1830, Nueva Granada componía, con Veneznela y Ecuador, la República de Colombia, ahora llamada Gran Colombia, dominada por Simón Bolívar. Tras su disolución, la República de Nueva Granada conoció algunos años de estabilidad, por ejemplo bajo la administración de Francisco de Paula Santander (1832-1837). A partir de 1858, la Confederación granadina emprendió un proceso de federalización que culminó con la existencia de los Estados Unidos de Colombia entre la Constitución de 1863 y la de 1886 (Estas fechas precisas deben ser tomadas con precaucion, bios ocurridos durante los meses y años anteriores que su punto de partida. En este sentido, el la Repuli contrar El final del siglo XIX fue marcado por la guerra de los Mil Días de 1899 a 1902. Hasta 1903, Panamá fue parte del territorio de la actual Colombia. 
guar estos distintos elementos para poder entender cómo persistió esta práctica ilegal y con qué matices temporales y tendencias regionales.

De los aspectos afines al tema del contrabando, el campo de la historia económica ha sido el más estudiado y el que cuenta con varios títulos que desbrozaron el terreno. Independientemente de cualquier interés por el contrabando pero incluyendo en sus análisis los aspectos necesarios para estudiarlo, algunos investigadores han querido descifrar la política fiscal y arancelaria durante el siglo xIX y la tensión entre proteccionismo y librecambio. ${ }^{5}$ Si bien lo económico es ineludible para entender la permanencia del contrabando, varias otras facetas también deben ser contempladas para dar una visión más completa del tema, por ejemplo, lo relativo al funcionamiento del ramo de aduanas, la penalización del contrabando y la distancia entre prácticas sociales y discursos oficiales acerca del mismo.

A pesar de su importancia, es muy poco lo que se ha abordado en la historiografía colombiana al respecto, dejando así un vacío bibliográfico enorme en relación con aspectos colaterales del contrabando: el mundo administrativo casi no ha ameritado estudios ${ }^{6}$ y menos aún la administración de aduanas, fundamental para entender la lucha contra el comercio ilícito y la administración de justicia. Este desdén se debe probablemente al carácter técnico y aparentemente aburrido del estudio de la administración pública, pero también al temor de abordar temáticas "nuevas" por la falta de estudios pioneros en esos campos y de ayudas prácticas, por ejemplo, la carencia de organigramas que faciliten el acercamiento a una administración en constante cambio, como fue el caso con los ramos de Aduanas y de Justicia. Asimismo, el tema de las prácticas sociales y culturales, si bien llama fuertemente la atención, no resulta ser de fácil acercamiento en las fuentes, puesto que las pistas para ello se encuentran esparcidas en distintos tipos de documentos.

A continuación, después de identificar nuestro objeto de estudio, se comparten algunos comentarios sobre los archivos consultados en el transcurso de la investigación, así como sobre los aspectos metodológicos a tomar en cuenta al tratar un fenómeno ilícito como lo es el contrabando, para finalizar con un balance general de los resultados obtenidos hasta la fecha.

De entrada, es necesario reflexionar sobre el carácter peculiar de este objeto de estudio. Por definición, la ilegalidad es todo aquello que la legislación prohíbe, limita o enmarca, es decir, se define por lo que no es

${ }^{5}$ Bushnell, Régimen, 1966; Bushnell, "Dos", 1977; Deas, "Problemas", 1993; Jaramillo, Meisel y Urrutia, Continuities, 1997; Melo, "Vicisitudes", 1987; Ocampo, "Librecambio", 1984; Tovar, "Lenta", 1987.

${ }^{6}$ En el caso de la Hacienda, existe la útil herramienta que constituye el trabajo de López, Historia, 1992. 
legal, lo cual exige remitirse efectivamente al ámbito legislativo para precisar lo que un determinado Estado ha caracterizado como ilícito. Ciertas prácticas pueden o no haber sido catalogadas como indebidas, y los límites de la legalidad pueden variar de un lugar a otro. Otro tema distinto, pero no menos interesante, es el de la percepción de la sociedad, o parte de ésta, frente a las prácticas consideradas por la norma como ilegal, así como la legitimidad que tiene el legislador a los ojos de las personas a las cuales se aplican las normas.

La observación anterior arroja consecuencias respecto a la documentación utilizable para la investigación sobre un asunto ilegal. El grueso del material que el investigador en ciencias sociales puede utilizar para el estudio de un fenómeno ilícito como el narcotráfico, la corrupción, el contrabando $\mathrm{u}$ otro tipo de ilegalidad, es principalmente de procedencia institucional pública, lo que constituye una paradoja de la investigación sobre cualquier tipo de ilegalidad, sea desde una perspectiva histórica o desde cualquier otra. De hecho, la información que permite documentar esos procesos ilícitos proviene en gran medida de las instituciones estatales de control y fiscalización. Por lo tanto, hay que tomar en cuenta que la documentación alcanzable por el investigador es de carácter represivo y constituye una mirada desde el Estado hacia prácticas no toleradas por él. Lo anterior constituye una característica que metodológicamente no puede perderse de vista: las fuentes fueron producidas para un fin fiscalizador y esto influye sobre la información contenida en ellas.

De la misma manera, no suele dejar huellas lo que es considerado normal por una sociedad determinada, no hay tampoco rastros de lo que no se registraba ante las autoridades y, por ello, escasas son las visiones dejadas desde la misma "clandestinidad". Lamentablemente para el historiador no se ha desarrollado una tradición epistolar entre actores al margen de la ley, de los mismos con sus familiares y amigos, y a su vez los que practican la ilegalidad no recurren a la práctica de plasmar sus reflexiones en diarios íntimos o escribir columnas periodísticas.

En cuanto al contrabando, en particular, se trata de un delito, es decir, es penalizado por la legislación vigente. ${ }^{7}$ Este delito económico ha recibido el calificativo de "sin víctima", puesto que no afecta a nadie directamente; lo anterior lo convierte en un delito de categoría menor frente a la lista de delitos que atentan contra las personas físicas o sus propiedades. Etimológicamente, contrabando significa contra el "bando" o edicto ${ }^{8}$ en otras palabras, una acción que va en contra de la norma legal.

${ }^{7} \mathrm{Si}$ bien esta afirmación es de carácter demasiado general, se aplica para la época colonial y el periodo republicano hasta nuestros días, aunque con evidentes variaciones.

${ }^{3}$ Diccionario de la Real Academia Española <www.rae.es>. 
Más concretamente, la definición de contrabando contiene dos ejes. ${ }^{9}$ Un primer significado tiene que ver con el hecho de no respetar una prohibición de comercio, sea de importación, sea de exportación, como es el caso actualmente del tráfico de sustancias psicoactivas o de armas, que son mercancías cuya circulación está totalmente prohibida o sometida a reglas muy estrictas; 'en general, su objetivo está relacionado con la salud pública o la seguridad. En un sistema mercantilista, esta interdicción recaía sobre el llamado "comercio extranjero", es decir, el intercambio de mercaderías con imperios distintos al propio. La segunda acepción de la palabra contrabando es más difundida en la actualidad: se trata del no pago del arancel que el Estado levanta a la introducción de bienes en otro país al paso de la frontera para ser consumidos en el mercado nacional. Se trata de una medida fiscal en el ámbito comercial, cuya meta es la de proveer ingresos públicos a la vez que protege la producción nacional contra una competencia proveniente del exterior.

En todo caso, sea por desacato a una prohibición total o parcial, sea por evadir un impuesto, se trata de un fraude, de una violación a la legislación fiscal vigente en materia comercial. Es importante notar desde la misma definición la presencia fuerte del Estado y de sus fronteras. De hecho, es el Estado el que fija, por los motivos que considera convenientes, la normatividad en materia comercial; la frontera que lo delimita con los demás espacios territoriales es el lugar donde se controla la legislación existente y hasta donde se ejerce la soberanía. En este sentido, se puede entender la importancia del tema del contrabando para el Estado: se trata de su capacidad para hacer acatar la legislación que ha expedido, así como del recaudo fiscal gracias al cual podrá pagar sus obligaciones internas y externas, invertir y eventualmente prosperar.

LOS ARCHIVOS PARA EL ESTUDIO DEL CONTRABANDO EN EL SIGLO XIX en Colombia

La información histórica que se encuentra sobre las prácticas de contrabando en Colombia en el siglo XIX proviene de varios horizontes que, como ya se subrayó, son en su mayoría de corte oficial. En primer y destacado lugar, hay que recurrir a los documentos elaborados por la entidad pública que era encargada de velar por la legalidad de los movimientos comerciales en las fronteras colombianas, así como de realizar el cobro de los derechos fiscales y, por ende, de reprimir el contrabando. La institución competente era la Administración de Aduanas, dependen-

${ }^{9}$ Petit, Dictionnaire, 1986. 
cia de la Secretaría de Hacienda. Los archivos de esta institución están localizados principalmente en el Archivo General de la Nación (AGN) de Bogotá, sección República, que proporciona una información abundante tanto por la cantidad de fondos en los cuales se aborda el tema del contrabando como por su calidad.

El fondo Contrabandos reúne este tipo de información para la década de 1821 a 1830, durante la cual Nueva Granada estaba inserta en la "Gran Colombia". Cada folio del tomo único de este fondo documental aporta datos valiosos. Se trata básicamente de procesos que ofrecen datos sobre las mercancías, las rutas, los contrabandistas y detallan la legislación aplicable y los pasos procesales. Para encontrar los procesos llevados a cabo en los años posteriores a 1830 y hasta mediados del siglo, aproximadamente, es necesario realizar pesquisas en varios otros fondos (que cuentan afortunadamente con catálogos), tales como Asuntos criminales, Congreso, Aduana de Santa Marta, Gobernación de Santa Marta, Gobernaciones varias, Ministerio Interior y Relaciones exteriores, Negocios judiciales, Anexo II: Administración de Aduanas-Administración de Tabacos-Secretaría de Hacienda.

Para la segunda mitad del siglo XIX, los archivos aduaneros están reunidos en el fondo Aduanas, el cual es de una riqueza excepcional en cuanto a asuntos relacionados con esta administración, mezclando informes económicos, facturas, actas de los remates, procesos y correspondencia con contenidos muy variados. Este fondo, organizado por aduana y luego en forma cronológica, cuenta con alrededor de 100 tomos que cubren el periodo federal de los Estados Unidos de Colombia y la regeneración centralizadora. Desafortunadamente dicho fondo no cuenta con un catálogo, lo que hace su consulta muy lenta y dispendiosa. Por esta razón, a pesar de que nuestro objetivo inicial era cubrir todo el siglo XIX se optó por "aprovechar" el fin del periodo federal para cerrar el estudio. Concretamente, se consideró más pertinente alcanzar a hacer una buena revisión de los documentos concernientes al periodo federal, abarcando las distintas fronteras del territorio nacional, en vez de tratar de alcanzar la guerra de los Mil Días de final del siglo XIX teniendo que privilegiar algunas regiones. De hecho, en los tomos relativos al periodo federal, se puede recoger información sobre las múltiples aduanas nacionales y documentar así no sólo los procesos levantados en ellas, sino el funcionamiento local de dicha administración en las aduanas de Arauca, Barranquilla, Buenaventura, Carlosama, Cartagena, San José de Cúcuta, Quibdo, Riohacha, Riosucio, Santa Marta, Tolú y Tumaco.

En resumidas cuentas, en los fondos citados se consiguieron los siguientes documentos:

1) Los procesos levantados en las aduanas al detectar contrabandos. 
2) La correspondencia entre las oficinas de aduana descentralizadas en los distintos puntos fronterizos del territorio nacional y la Secretaría de Hacienda, cuya sede era la ciudad de Bogotá.

3) Los informes internos a cada aduana y otras notas internas.

4) La reglamentación oficial vigente.

5) Las cartas que ciertos comerciantes dirigieron a la administración de aduanas relacionando los inconvenientes que enfrentaban en sus negocios.

Esta documentación hizo posible informarse en tres direcciones: a) los procesos permitieron recopilar datos concretos sobre las modalidades utilizadas para efectuar el contrabando, las mercancías decomisadas, los lugares de aprehensión, las rutas seguidas por la mercancía, las personas involucradas y las penas impuestas; b) la situación particular a cada aduana en relación con el contrabando, donde se encontró información general sobre las modalidades, las mercancías, los lugares y rutas, los contrabandistas, las penas, las dificultades de vigilancia y las rondas del resguardo; c) las leyes, los decretos y las circulares oficiales relacionadas con el contrabando que permitieron conocer el marco legal vigente y su evolución.

Las fuentes útiles para documentar el fenómeno de contrabando en el siglo XIX no solamente proceden de los archivos de la administración de aduana, autoridad directamente competente. Otra valiosa fuente de información está constituida por las Memorias de Hacienda presentadas anualmente al Congreso por el secretario de Hacienda en turno, ${ }^{10}$ donde se ofrece un balance de los asuntos relativos al ramo de Hacienda y en particular en cuanto al comercio de la república y a la situación de los estancos. Señalaban, por lo tanto, las cuestiones relacionadas con el contrabando y planteaban medidas para remediar los eventuales problemas. Se trata de un material muy rico no sólo en datos comerciales puntuales, sino también en el análisis del comercio ilícito y en planteamientos sobre las medidas a aplicar. También presentaban el punto de vista de la más alta autoridad económica sobre la administración de las aduanas nacionales, y en este sentido permiten conocer el problema desde la perspectiva oficial y entrever los cuestionamientos que se hacían a este nivel en cuanto al contrabando.

La prensa constituye otra fuente sustancial para abordar el comercio ilícito. Los periódicos decimonónicos, oficiales y no oficiales, nacionales y regionales contienen abundante información relacionada con el contra-

${ }^{10}$ Algunos secretarios de Hacienda fueron posteriormente importantes figuras nacionales: José María del Castillo y Rada (1823, 1826 y 1827), Francisco Soto Montes (1833, 1834, 1835, 1836 y 1837), Manuel Murillo Toro (1851 y 1852), Rafael Nunez (1856), Miguel Samper Hacienda se pueden consultar en la Biblioteca Nacional de Bogotá. 
bando: se publicaban las leyes, los decretos y los comunicados gubernamentales, se insertaban artículos de los secretarios de Hacienda $\mathbf{u}$ otras figuras públicas, se avisaba ocasionalmente de los remates públicos de las mercancías confiscadas como contrabando, se abría espacio a las discusiones sobre las cuestiones de actualidad económica, comercial y fiscal, así como a las quejas de comerciantes acerca de varios tópicos. En el caso colombiano, en el siglo XIX, la mayoría de los periódicos tuvieron una vida muy corta $y$, para revertir esta consecuente discontinuidad, se debe revisar un amplio número de periódicos consultables en la Biblioteca Nacional de Bogotá. Por un lado, estaban las gacetas oficiales y los periódicos "constitucionales" de cobertura nacional, así como regional durante el periodo federal (Antioquia, Chocó, Sur-Occidente), ${ }^{11}$ y también de boletines sectoriales de Hacienda, Justicia y sobre todo Comercio. $^{12}$ Por otro lado, dentro de la prensa no oficial se encontraba la que tenía vocación nacional y era editada en Bogotá, y la que se publicaba regional y localmente, cubriendo así la costa caribe, con periódicos de Cartagena, Mompox, Riohacha, Santa Marta y Barranquilla, y la región de Antioquia y del Chocó. ${ }^{13}$ Adicionalmente, tanto en la prensa como en unos cuantos folletos impresos consultables en la sala de Raros y Curiosos de la Biblioteca Luis Ángel Arango de Bogotá, varios comerciantes y funcionarios públicos revelaban su desagrado relacionado con la práctica del contrabando, sus quejas frente a la legislación vigente, sus desacuerdos ante las prácticas de sus colegas y sus reacciones en defensa de su honradez ante las acusaciones de contrabando. ${ }^{14}$

"I Gaceta de Colombia, 1822; Gaceta de la Nueva Granada, 1832 y 1834; Gaceta de Cartagena de Colombia, 1822-1824 y 1831; Mercurio del Consulado de Cartagena, 1831; Constitucional del Magdalena, 1835; Constitucional de Cartagena, 1836; Gaceta de Cartagena, 1837-1838; El Constitucional Antioqueño, 1831-1832; El Antioqueño Constitucional, 1847; Constitucional del Choco, 18351837; Constitucional del Cauca, 1832-1835; Constitucional de Popayán, 1835-1836; Gaceta del Cauca, 1841; Anales del Municipio, 1880-1881.

${ }^{12}$ Registro Oficial de Hacienda, 1834; Repertorio Judicial de la Nueva Granada, 1848; Repertorio Judicial, 1850; El Economista, Órgano de la Cámara de Comercio, 1879; El Comercio. Boletín 188 Órgano de los micreses Comerciales de Barranguilla 1874 y 1877-1878 y 1882; El Semanario Comercial, 1881.

El Neo-Granadino, 1848 y 1851; La Bandera Nacional, 1838; El Dia, 1845-1846; La Época, 1884; El Porvenir, Periódico de la Juventud, 1850; El Lucero de Calamar, 1834; El Momposino, 1846; El Riohachero, 1848-1849; El Eco de la Juventud, 1849; El Amigo del País, 1835; La SituaChoco, 1855; Eco del Atrato, 1878; El Atratense, 1880.

${ }_{11}^{1}$ Unos ejemplos de ello son Miguel Cotes, "Un mentís" (Riohacha, 7 de octubre de 1847), La Gaceta Mercantil, núm. 3, 12 de octubre de 1847, p. 7; Manuel Urrutia, El Honor Ultrajado pero No Manchado, 20 de abril de $1858,32 \mathrm{pp}$. 
Finalmente, en los relatos que dejaron los viajeros extranjeros que visitaron el país se pueden conseguir comentarios acerca del precario estado de las vías de comunicación y descripciones de los objetos de consumo que seguían la moda europea, tales como los objetos de decoración interior, los textiles, los artículos de belleza y aseo, los bienes comestibles y los licores, etc. En algunas ocasiones, estos viajeros insistían en el recurso al contrabando que caracterizaba la forma de obtener estas mercancías; sus relatos permiten darse cuenta de los gustos y de la demanda de objetos de fabricación extranjera..$^{15}$

Como se puede comprobar con las fuentes reseñadas y utilizadas en nuestra investigación, los recursos existentes para estudiar el contrabando son múltiples e incluyen sobre todo archivos oficiales, pero también documentos de carácter privado; documentos de destinatarios puntuales, así como artículos o folletos publicados, tanto documentos manuscritos como impresos. El acervo documental contenido en los archivos de la Administración de Aduanas debe ser complementado por otras fuentes, de tal manera que se pueda ofrecer un punto de vista más amplio de la situación. La complementariedad de las fuentes se da en varios niveles dado que abarca el aspecto cronológico, el cual se comentará más adelante; las perspectivas, como el aspecto administrativo, legislativo, judicial, social y cultural, etc.; y los autores, ya sean las autoridades, los comerciantes, etc. En su gran mayoría y a nuestro conocimiento, las fuentes de archivo señaladas no habían sido revisadas (excepto las Memorias de $\mathrm{Ha}$ cienda que han sido utilizadas por los historiadores económicos) y menos con un cuestionario de esta índole. ${ }^{16}$

No hay que perder de vista otras fuentes oficiales probablemente interesantes, tales como los fondos de Guerra y Marina, Relaciones exteriores y Asuntos consulares de la sección República del Archivo General de la Nación; las Memorias anuales de los secretarios de Relaciones Exteriores al Congreso y los archivos judiciales. A su vez, la correspondencia privada y las memorias personales tanto de hombres políticos como de comerciantes y eventualmente los testamentos de comerciantes y personas de las clases acomodadas, aportan probablemente miradas complementarias sobre el tema. Asimismo, los archivos departamentales y locales ayudarían sin duda a conocer más a fondo las particularidades regionales del contrabando y

${ }^{15}$ A modo de ejemplo, los siguientes viajeros dejaron relatos: Gaspar Theodore Mollien, Cosselman, 1825-1826; John P. Hamilton, 1827; J. Steuart, 1836-1837; Agustín Codazzi, 1856, y Alfred Hettner, 1882-1884. Vale subrayar que el caso colombiano no es el único: aparte de las investigaciones de Bernecker y de Mayo para el México decimonónico, no tenemos conocimiento de otros bando, 1994; Mayo, "Consuls", 1987. 
de su lucha. Por el tamaño de la empresa emprendida con las fuentes anteriormente reseñadas, hasta la fecha no hemos alcanzado revisar esta última documentación.

\section{Dificultades METODOLÓGicAs}

Una primera dificultad tiene que ver con la cobertura espacial y temporal que se logra gracias a las fuentes reunidas. Para la primera mitad del siglo XIX, los datos encontrados permiten dar un buen panorama del contrabando en la costa caribe colombiana, desde la Guajira hasta el golfo de Urabá, pero informan muy poco sobre las demás fronteras marítimas o terrestres del país. Este hecho se explica por el carácter fundamentalmente atlántico de los vínculos comerciales de Nueva Granada. Además, esta documentación es mucho más numerosa para los puertos habilitados, es decir, Cartagena, Santa Marta y Riohacha, que para el resto de la amplia fachada atlántica. Lo anterior se debe a la escasa vigilancia que ejercían las autoridades en los lugares alejados, lo que por lo demás presentaba claras ventajas para realizar un contrabando muy activo.

Para el periodo federal, la información resulta mucho más amplia, de tal forma que adquieren visibilidad los límites territoriales de Colombia en todas las direcciones, dejando aparecer seis regiones específicas: Riohacha y la Guajira con la aduana de Riohacha, la costa entre Riohacha y el golfo de Urabá con las aduanas de Barranquilla, Cartagena, Santa Marta y Tolú, el golfo de Urabá y el río Atrato con las aduanas de Riosucio y Quibdo-Turbo, la costa sur del Pacífico con las aduanas de Buenaventura y Tumaco, la frontera terrestre con Ecuador con la aduana de Carlosama y la frontera terrestre y fluvial con Venezuela con las aduanas de Arauca y San José de Cúcuta. El hecho de que la actividad del resguardo móvil se haya desarrollado frente a la primera mitad del siglo permite que los archivos de cada aduana incluyan las aprehensiones hechas no sólo en el puerto marítimo, fluvial o seco, sino también en cualquier otro punto circunvecino donde los guardas realizaban sus rondas.

En cuanto al aspecto temporal, los procesos abundan para la primera década independiente antes del fin de la "Gran Colombia", y existe también bastante información para documentar el contrabando casi hasta finales de los años treinta, mientras que los años cuarenta y cincuenta no presentan un balance tan positivo. Para justificar esta evidencia, se debe recordar que la administración de Santander (1832-1837), particularmente tranquila en el plano militar, pudo ser intensa en actividad administrativa, y que la guerra de los Supremos de 1839 a 1842 y la lenta recuperación posterior golpearon este entusiasmo y explican la disminución de las 
fuentes disponibles y eso hasta el fin de los años cincuenta, con la notable excepción de los años 1845 a 1850 durante los cuales se debatieron intensamente los asuntos relativos al librecambio y al desmantelamiento de los estancos y monopolios. Con el periodo federal se vuelven a encontrar las huellas de una intensa actividad administrativa, por lo menos en el ramo que aquí nos interesa.

Un segundo inconveniente mayor tiene que ver con la cuantificación del contrabando. Si bien las Memorias de Hacienda trataban de calcular la dimensión del contrabando y de las pérdidas para el Tesoro, es muy incierto el tamaño real del comercio ilegal y su impacto. Para que se haya registrado el contrabando tenía que haberse realizado una aprehensión: no se puede saber a ciencia cierta qué porcentaje del contrabando total constituyen los casos que se conservaron en los archivos. El caso del contrabando de oro es particularmente complicado de cuantificar, ya que casi no se registraban aprehensiones por parte de las autoridades, lo cual se debe al hecho de que, por un lado, el oro en polvo se escondía fácilmente $^{17} y$, por el otro, para decomisar el oro había que probar que estaba destinado a la exportación. ${ }^{18}$ Además, los procesos no recurrían al mismo sistema de medición para cuantificar las cargas decomisadas; para el tabaco se utilizaban medidas tan disímiles como arrobas, libras, sacos, bultos, manojos o número de cigarros; y para la sal se hablaba de piedras, ladrillos, quintales, kilogramos, libras, cargas, sacos, bultos o bolas. $\mathrm{Si}$ bien en varios casos se puede convertir las medidas y así homogeneizar para poder sumar, una cantidad significativa de procesos ni siquiera ofrecen una indicación cuantitativa, sino simplemente la calidad del producto decomisado. En este sentido, las equivalencias que en ciertas ocasiones se pueden realizar no permiten dar una cifra exacta de la cantidad de mercancía contrabandeada que las autoridades incautaron.

En tercer lugar, la amplia gama de fuentes utilizables no significa que se puedan responder todas las inquietudes planteadas, en particular, los interrogantes acerca de la vivencia y las opiniones de los propios contrabandistas y sus cómplices, y eso por el carácter fundamentalmente oficial de los documentos. Se encuentran muy pocos documentos, comparativamente hablando, que reflejan la posición de los contrabandistas, es decir, sus puntos de vista sobre sus propias actividades. Las fuentes encontradas al respecto, y que se detallarán más adelante, usan el recurso literario para expresar la inconformidad de los contrabandistas con las autoridades y, de manera más general, el concepto en el cual las tenían.

${ }_{17}$ J. J. I., "Iibre exportación del oro, parte n", El Dia, núm. 343, 22 de marzo de 1846. ${ }_{18}^{18}$ Mariano Montilla, prefecto general del Magdalena al ministro de Estado en el Departamento de Hacienda, Cartagena, julio de 1829, en Archivo General de la Nación (en adelante AGN), sección República, fondo Contrabandos, leg. 1, fs. 488-506. 
En relación con lo anterior, conocer la trayectoria de las personas involucradas en el contrabando, sea por practicarlo, sea por encubrirlo desde un puesto oficial, no suele ser posible. Por un lado, los mismos contrabandistas no redactaron diarios íntimos ni sostuvieron correspondencia donde se pudieran descubrir sus pensamientos, sistemas y contactos y, por su lado, los casos de corrupción que las autoridades evidenciaron no fueron numerosos. A su vez, cuando los procesos por contrabando mencionan el nombre del contrabandista, éste no siempre es una pista suficiente, ya que no correspondían a grandes comerciantes, sino más bien a comerciantes medianos o pequeños, intermediarios, cargadores, etc. Proceder a armar las redes de comerciantes y sus relaciones eventualmente políticas daría probablemente un resultado muy interesante, pero después de una ardua tarea para el investigador que no cuenta con muchas herramientas, como podrían ser los diccionarios de personas y lugares, las listas de funcionarios por ramo de la administración pública, etc. Este trabajo se tendría entonces que realizar lentamente confrontando los documentos encontrados con otras fuentes primarias y rastreando los nombres en la historiografía existente.

\section{AlgunOS RESUltados}

A pesar de estos problemas y gracias a las fuentes recopiladas, se llegan a algunos resultados interesantes en cuanto a los rasgos del contrabando, tanto en lo que tiene que ver con los productos, los lugares, las rutas y las personas involucradas, como con las posibles explicaciones de su permanencia en el tiempo, entre las cuales están la política arancelaria, el funcionamiento de las aduanas locales, la penalización del contrabando y el arraigo de las prácticas sociales.

Un primer elemento clave es el de la política económica que estuvo caracterizada por el mantenimiento del proteccionismo claramente heredado de la colonia hasta las reformas liberales de mediados del siglo XIX, y menos abiertamente en la segunda mitad del siglo, en un contexto de aguda necesidad fiscal y de precaria industria nacional que hacía el país dependiente del exterior para muchos de los productos manufacturados. ${ }^{19}$

Hasta 1850, se conservaron los estancos de tabaco, pólvora y naipes, así como las restricciones severas en el comercio del oro. ${ }^{20}$ Las reformas de tendencia liberal, logradas a partir de la segunda mitad de la década

19 Tovar, "Lenta", 1987; Ocampo, "Librecambio", 1984, pp. 248-249.

${ }^{20}$ Nieto, Economía, 1942, p. 182; Palacios y Safford, Colombia, 2002, p. 336; Galindo, Historia, 1874, p. 32; Bushnell, Régimen, 1966, pp. 97 y 99. 
de los cuarenta, abrieron campo a una disminución de la protección, por lo menos en teoría, puesto que la tensión continuó siendo constante en la práctica por los vaivenes de las políticas económicas que revertían regularmente las disminuciones de los niveles de los aranceles. ${ }^{21}$

De esta manera, en vez de depender de consideraciones comerciales, el valor de los aranceles era fijado con la idea de producir ingresos al Tesoro público, pero debía tener en cuenta el riesgo de contrabando si la tarifa era alta. Se estableció así una relación triangular constante entre la política arancelaria, la renta de aduanas y el comercio ilícito. Para los actores del contrabando, la tendencia proteccionista, empeorada por la crisis de abastecimiento de ciertos estancos, creaba un marco favorable a la actividad ilícita; a su vez, el argumento de la nefasta importancia de dicha actividad se convirtió en un medio de presión en la reivindicación de una mayor libertad comercial.

Otro inconveniente de los aranceles radicaba en que las sucesivas formas utilizadas para percibir los derechos de aduanas presentaban deficiencias: si se aplicaba el sistema ad valorem, que prevaleció durante la primera mitad del siglo, la verificación de cada cargamento y de cada paquete demoraba la introducción y podía producir daños a las mercancías, mientras que si el sistema era el del peso bruto de las mercancías, lo cual fue el caso a partir de mediados de la década de los cuarenta, los textiles burdos pagaban un impuesto mayor a las telas finas privilegiando así las elites urbanas en detrimento de las clases populares. ${ }^{22}$

En este contexto, durante la primera mitad del siglo XIX, el contrabando se concentraba en la costa caribe, lo cual se debía al hecho de que, además del mencionado problema de las fuentes y del número de habitantes de la zona, por un lado, la orientación comercial neogranadina era casi exclusivamente hacia el Caribe, debido a la importancia de las islas caribeñas como lugar de paso de las mercancías entre Europa y Colombia, particularmente Jamaica para los ingleses y Curazao para los holandeses; y por otro lado, con la inserción de Nueva Granada en la "Gran Colombia" no se visibilizaban fronteras internas hacia el sur y hacia el este de la república. Los ríos Magdalena, Sinú y Atrato eran los principales canales de alimentación de los mercados del interior, como Bogotá, Medellín y la región de Santander, donde se consumían los productos de contrabando. A pesar de la predominancia del comercio ilícito a través de la fachada caribeña, existía en menor medida un contraban-

${ }^{21}$ Ocampo, "Librecambio", 1984, p. 244; Melo, "Vicisitudes", 1987, pp. 146, 150-154; López, Historia, 1992, p. 122. ${ }_{22}$ Ocampo, "Librecambio", 1984, pp. 250 y 255; López, Historia, 1992, p. 152; Melo,
"Vicisitudes", 1987, p. 150; Safford, "Comercio", 1965, p. 158. 
do que ingresaba al país por el costado Pacífico, principalmente hacia el sur de la misma, donde había mayor población que en el norte. ${ }^{23}$

Los productos que fueron canalizados por las vías ilícitas reflejan no sólo la base productiva nacional y local y las necesidades de consumo interno, sino también la tendencia de la política económica que, como se señaló, conservó los estancos y las prohibiciones de comercio. De hecho, el tabaco, que estaba sometido a un monopolio estatal, conocía un movimiento ilegal bidireccional: el tabaco extranjero en procedencia de Virginia en Estados Unidos así como de Cuba ingresaba al territorio nacional, mientras que una parte de la producción local salía del país rumbo al exterior. ${ }^{24}$ En sus dos dimensiones, este tráfico era prohibido por las autoridades, que, sin embargo, no abastecían a cabalidad el estanco, permitiendo así que los contrabandistas justificasen el contrabando. ${ }^{25} \mathrm{La}$ pólvora y los naipes, también estancados durante una parte de la década de los veinte, conocieron una lógica similar, ${ }^{26}$ con la misma falta de abastecimiento en el caso del estanco de pólvora. ${ }^{27}$ Los licores, en particular el ron procedente de Jamaica y la ginebra que llegaba por Curazao, vivieron un auge de contrabando entre 1823 y 1826, años durante los cuales eran de prohibida introducción. ${ }^{28}$ A su vez, la exportación de oro en barra y polvo, que contaba con una reglamentación estricta hasta mediados de siglo, se realizó en cantidades importantes mediante el contrabando. En cambio, casi no había exportación de productos locales como el algodón y el palo de mora ${ }^{29}$ probablemente porque no sufrían de una legislación restrictiva y porque no habían encontrado un mercado importante en el extranjero. Un último grupo de productos introducidos ilegalmente no sufría restricciones comerciales, pero tenían un mercado muy importante en el país: los textiles de todas las calidades y las

${ }^{23}$ Para los casos ocurridos en la costa caribe: AGN, sección República, fondo Contrabandos, tomo ámico. Para los casos ocurridos en la costa pacífica: Constitucional del Cauca, núms. 135, 144, 145 y 146, 1835; Constitucional de Popayán, núm. 185, 1836; Constitucional del Choco, núms. 27 y 35, 1836. ${ }_{24}^{24}$ AGN, sección República, fondo Contrabandos, leg. 1, ff. 25-55, 463-481, 514-515, 521570; fondo Gobernaciones varias, leg. 124, f. 357;
630; fondo Asuntos criminales, leg. 17, fs. 177-360.

${ }_{25}$ fondo Asuntos criminales, leg. 17, fs. 177-360. Cartectur da, Cartagena, 1830, en AGN, sección República, fondo Contrabandos, leg. 1, f. 440; Proceso, Sonsón, 1824, en AGN, sección República, fondo Contrabandos, leg. 1, fs. 25-55; Un empleado

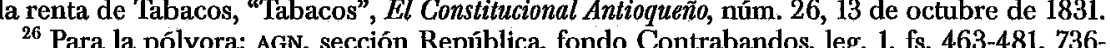
740, 804-834 y 842-859; para los naipes: AGN, sección República, fondo Contrabandos, leg. 1, fs. $108-280,425-428$ y $514-515$

${ }^{27}$ Proceso, Cartagena, 1826, en AGN, sección República, fondo Contrabandos, leg. 1, fs. 804-834 y 842-859.

${ }^{28}$ Bushnell, Régimen, 1966, p. 179; AGN, sección República, fondo Contrabandos, leg. 1, fs. 463-481, y fondo Gobernación de Santa Marta, leg. 1, fs. 56-64 y 95-96.

${ }^{29}$ Madera de la cual se extrae un colorante utilizado para tinturar los textiles. 
manufacturas de lujo como los perfumes, las pomadas, los peines, las porcelanas y la cristalería llegaban ilícitamente desde Europa en grandes cargamentos, reflejando así un consumo a la moda europea por parte de las clases urbanas acomodadas. ${ }^{30}$

Para el periodo federal, se observan seis regiones fronterizas por las cuales se importaban mercancías de contrabando. Cada una de estas zonas conoció una dinámica específica de comercio ilícito. Por ejemplo, en el Sur-Occidente, se introducían cantidades significativas de sal y de papel, tanto por la costa del Pacífico como por la frontera terrestre con Ecuador, mostrando la relación directa de esta región con el exterior y las necesidades locales de consumo. En la Guajira se realizaba un intercambio de productos locales, como las maderas y los animales, ${ }^{31}$ con mercancías extranjeras, principalmente en barcos holandeses y en ocasiones con la participación de indígenas en ese tráfico. De manera general, la costa caribe seguía siendo importante en cuanto a contrabando, $y$, respecto a los productos, los textiles y las manufacturas extranjeras seguían importándose por la vía ilegal y alimentaban sin mayores diferencias las diferentes regiones fronterizas. Desde 1850, Panamá había ido reemplazando paulatinamente a Jamaica como principal punto de paso de los bienes hacia las dos costas colombianas. El contacto ilegal del Sur-Occidente también se hacía con varios puertos de la fachada del Pacífico chileno, peruano y ecuatoriano. Desde el océano Pacífico, el río Patía era una importante vía de comercio ilícito. ${ }^{32}$

Además de la explicación por la política arancelaria y económica en general, se ha trabajado alrededor de tres grandes ejes de análisis para entender la permanencia del comercio ilícito. En primer lugar, el funcionamiento de la administración de aduanas amerita atención en la medida en que era plagado de problemas prácticos que hacían muy difícil la vigilancia efectiva de las importaciones y exportaciones. Se puede señalar el tema de la ubicación de ciertos puestos de aduana, por ejemplo, sobre el río Atrato. Este asunto constituyó, en los años treinta y nuevamente en los años sesenta y setenta, un verdadero dolor de cabeza para las autoridades: ninguno de los lugares sucesivamente considerados para tal fin (Matuntuvo, Quibdo, Turbo, Riosucio) presentaba condiciones óptimas para el control. ${ }^{33}$ Esta indefinición dejó un amplio campo al contraban${ }^{30}$ Véase en particular: AGN, sección República, fondo Contrabandos, leg. 1, fs. 108-280, 463-
481, 507-511 y 571-701, así como La Gaceta Mercantil, núms. 130, 133, 138, 144, 148 y 152, 1850 . ${ }^{31}$ Los archivos no precisan de qué animales se trataba, pero se puede pensar que se exportaba ganado vacuno del sur de la Guajira y cabrío de la misma Guajira.

AGN, sección República, fondo Aduana

14,25 y 35,1836 , y núm. 39, 1837; Parsons, Urabo 1996, ; 
do. También intervinieron aspectos como la escasez de dotación material de las aduanas -en cuanto a edificios, embarcaciones y herramientas de trabajo como balanza y anteojo- y referentes al personal aduanero respecto a la falta de efectivos y su débil remuneración. ${ }^{34}$ Estos elementos representaban un sin fin de limitaciones para los empleados encargados de velar por la legalidad comercial.

El segundo punto de interés es el de la penalización del contrabando. Para estudiar la coincidencia entre la teoría y su aplicación se confrontó la legislación con la información contenida en los procesos. De esta forma, es posible decir que existió una brecha entre las penas previstas y las efectivamente aplicadas a los contrabandistas. Si bien la cantidad de mercancía ilícita decomisada es significativa y representativa de las aprehensiones realizadas, la suerte de los contrabandistas no reflejaba lo previsto por la legislación. Durante la déçada de los veinte, la encarcelación era requerida cuando la mercancía de contrabando sufría una prohibición, pero los interesados recurrieron a la posibilidad de evitarla pagando una multa significativa. ${ }^{35}$ Durante el periodo federal, ya no se requería la prisión, sino que los contrabandistas se veían sometidos al pago de una multa. La novedad consistió en que los comerciantes recurrían a métodos sofisticados para burlar la vigilancia: declaraban mercancías como si fueran de una clase menor de la que era en realidad y escondian su cargamento bajo una primera capa que correspondía a la declarada. Adicionalmente, las facturas presentaban muchas deficiencias en cuanto al peso y a la clase de mercancía: estas deficiencias eran consideradas como errores cuando en ocasiones eran voluntarias y tenían como fin la introducción ilegal. Las autoridades debatieron lo que para algunos secretarios de Hacienda era un contrabando técnico, pero no se logró modificar las penas ni introducir en la legislación la idea del error voluntario con fines ilícitos. ${ }^{36}$

Aduanas, Aduana de Quibdo, t. 1, fs. 131-134; Aduana de Cartagena, t. 2, f. 194; Aduana de Riosucio, tomo único, fs. 4-5, 288 y 518; Samper, Memoria, 18\%; Camacho, Memoria, 187. ${ }^{34}$ Sobre este particular, los documentos abundan en AGN, secclon Republica, fondo Aduana Sobre la legislación vigente. Lopez, Kistoria, 1992, p. 66, De" "C de 23 de novembre de 1826 que impone penas a los defraudadores de la Hacienda pulc "Cicular de 14 de julio de 1828 " que lo modica, anbos en Cosifos cuales se aplicó la pena de encarcelacion: AGN, seccion Repúb, minales, leg. 4, fs. 361-371, y leg. 17, fs. 177-360; fondo Negocios judiciales, leg 4. fs. 104-106. ales, leg. 4, fs. 361-37, y leg. 17, fs. 177-360; fondo Negocios judiciales, leg. 4, fs. 104-106. Sódigos de Aduanas de 1864 y 1872. Los casos se encuentran en AGN, sección República, fondo Códigos de Aduanas de 1864 y 1872 . Los casos se encuentran en AGN, sección República, fondo
Aduanas, Aduana de Barranquilla y Tumaco principalmente. En cuanto a la creencia en la Aduanas, Aduana de Barranquilla y Tumaco principalmente. En cuanto a la creencia en la
buena fe: Cuenca, Memoria, 1866 ; Samper, Memoria, 1870. En cuanto a la creencia en el fraude: Parra, Memoria, 1874; Roldán, Memoria, 1883; El administrador de la Aduana al secretario de Hacienda, Barranquilla, 26 de noviembre de 1877, en AGN, sección República, fondo Aduanas, Aduana de Barranquilla, t. 2, f. 85; "Contrabando", El Promotor, núm. 349, 17 de noviembre de 1877; "Contrabando en la aduana", El Promotor, núm. 352, 8 de diciembre de 1877. 
En tercer lugar, se encontró un evidente abismo entre los discursos oficiales y las conductas sociales. Los discursos oficiales descalificaban el contrabando, en primera instancia, por su impacto nefasto sobre los ingresos fiscales de la república y, en segundo lugar, por la inmoralidad que generaba entre la población. La inestabilidad comercial era igualmente apuntada en la medida en que el contrabando tenía como efecto distorsionar los precios de las mercancías. ${ }^{37}$ A pesar de la intención discursiva de promover un modelo republicano moderno en el sentido de lealtad de los ciudadanos al Estado, las prácticas ilícitas seguían reproduciéndose en niveles altos. El hecho de que la corrupción y el soborno fueran recursos frecuentemente utilizados ${ }^{38}$ muestra una pobre integración del mensaje republicano por parte de la población, incluso considerando que una coincidencia total entre el ideal y la práctica suele revelarse imposible. Se nota una continuidad de conductas de tipo colonial en la utilización de los cargos públicos en beneficio propio en la administración de aduanas, así como en el sistema judicial donde se percibe de manera muy clara, por lo menos para la segunda mitad del siglo XIX, el funcionamiento de redes de poder familiares y amistosas con el fin de impedir la aplicación de castigos. $^{39}$ También era importante entre los contemporáneos el tema del honor que se observa gracias a las defensas ante las acusaciones que eran difundidas por medio de los periódicos y de impresos cortos. ${ }^{40}$

Dos testimonios procedentes de autoridades en el campo de la $\mathrm{Ha}$ cienda pública, el primero de Abraham Moreno, secretario de Hacienda del estado de Antioquia, y el segundo de Aníbal Galindo, secretario de Hacienda de la Unión, apuntaban respectivamente en 1867 y 1884 dos características interesantes de las conductas sociales en el país: para el

${ }^{37}$ Lo anterior se desprende de la lectura de los decretos y las circulares relativas al contrabando, así como de las Memorias de Hacienda.

Varias cartas internas a la administración de aduanas señalan casos de corrupción y soborno: AGN, sección República, fondo Contrabandos, leg. 1, fs. 1-24, 1921; fs. 281-292, 1822; fs. 571-701, 1829; fs. 176-177, 1831; fondo Aduanas, Aduana de Tumaco, t. 6, f. 838, 1877; Aduana de Riohacha, t. 5, f. 194, 1872; Aduana de Quibdo, t. 1, fs. 739 y 805, 1869; Aduana de Riosucio, tomo único, f. 815, 1873; Aduana de Riosucio, tomo único, fs. 696-699, 1873; Aduana de Buenaventura, t. 2, f. 891, 1871; Aduana de Tumaco, t. 4, fs. 595-597 y 888-890, 1871; Aduana de Tumaco, t. 6, fs. 308-310 y 498-500, 1876; Aduana de Carlosama, t. 1, f. 403, 1866; t. 2, f. 223,1868 ; t. 2, fs. 64 y 480, 1869-1870; t. 3, f. 111, 1872; Aduana de Arauca, t. 1, fs. 137 y $201,1865, y$ f. 429,1873 .

${ }^{39}$ AGN, sección República, fondo Aduanas, Aduana de Carlosama, t. 1, f. 539, 1867; Aduana de Tumaco, t. 3 , f. 417,1869 y t. 4 , fs. 841 y 879,1871

${ }^{40}$ Miguel Cotes, "Un mentís" (Riohacha, 7 de octubre de 1847), La Gaceta Mercantill, núm. 3, 12 de octubre de 1847 , p. 7; "Contrabando", El Comercio. Boletín Industrial. Órgano del 1884; Manuel Urrutia El Honor Ultrajado pero No Manch de Come

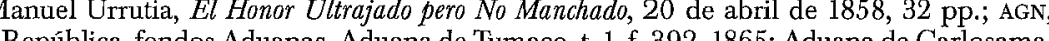
t. 3 , f. 464,1873 y t. 4 , f. 936,1879 . 
primero, existía una percepción moral errada que hacía que la actividad comercial ilícita era vista como una "viveza" que, mientras era desconocida por las autoridades, no tenía nada de reprehensible ${ }^{41} y$, para el segundo, el problema radicaba en "las debilidades que nacen de la falta de independencia personal en que se vive en estas sociedades parroquiales, donde somos amigos o conocidos, y que permite a los audaces y especuladores esconder su interés privado bajo la capa de un interés público". ${ }^{42}$

Por su lado, las opiniones de los contrabandistas se traslucen en unos cuantos documentos. En primer lugar, recordemos que en ciertos procesos los involucrados aludían a la falta de abastecimiento de los estancos por el propio Estado, lo que según ellos los justificaba para proveer los mercados de manera ilegal y así suplir la demanda. En segundo lugar, en su supuesto testamento fechado de 1834, un ex funcionario público, Silvestre Cotes, de Riohacha, quien reconocía haber defraudado al fisco en varias ocasiones, mencionaba varios elementos a su favor. Además de subrayar la problemática educación que había recibido, aclaraba que su uso privado de los fondos públicos debía entenderse fácilmente por el hecho de que para él lo que es público es de todos y, por lo tanto, de cada uno: "Los fondos del gobierno como del público, juzgué me pertenecían siendo como soy una parte de aquel todo soberano". Por medio del testamento pretendía ponerse a salvo para poder entrar al cielo repartiendo su fortuna entre el capitán de la goleta holandesa Dorotea por los daños que pudo haberle ocasionado aconsejándole traer efectos de contrabando, y el Tesoro público por haber aprovechado su puesto oficial efectuando varias introducciones ilícitas. ${ }^{43}$

En tercer lugar, un artículo del ensayista Manuel María Madiedo, publicado en 1848 en la sección Literatura del periódico El Neo-Granadino, denunciaba las prácticas ilegales de los representantes de las autoridades y su doble moral. El cuento reflejaba la deshonestidad de los guardas nacionales que, además de decomisar tabaco, le robaban al contrabandista dicha mercancía, así como los demás bienes con los que cargaba. En boca del "contrabandista", los guardas son descritos como "ladrones hambrientos que viven del sudor de los demás hombres [...] no querría nunca regalar infamemente a unos canallas el pan de mis hijos [...] Infames, este tabaco es el pan de seis hijos, de su madre, y de sus pobres abuelos que no pueden valerse." Los representantes de las autoridades son presentados como personas que no merecían respeto, lo que le revertía legitimación y justificación a una práctica teóricamente ilegal, pero

${ }^{41}$ Moreno, Informe, 1867, p. 16.

${ }^{42}$ Galindo, Memoria, 1885, p. 174

${ }^{43}$ Al mundo, 1834. 
aceptada como una actividad comercial digna de reconocimiento. Además, el cuento hace alusión también a la corrección de los supuestos defraudadores, tanto por el respeto entre ellos de las reglas de intercambio de mercancías, como por la confianza que inspiraban. ${ }^{44}$

\section{OBSERVACIONES FINALES}

Como se pudo apreciar, las fuentes para estudiar el contrabando en el siglo XIX en Colombia son numerosas. Incluso, esta misma abundancia de archivos a recopilar termina abrumando al investigador que no alcanza, sino con tiempo y dedicación, a revisar la información a su disposición. Obviamente, si lo anterior puede sonar a queja, también debe ser asumido en forma positiva por las sorpresas que todavía le reservan probablemente las fuentes. Por otro lado, dicha documentación presenta varias limitaciones para conocer y analizar los múltiples aspectos que contiene el tema. Además de los evidentes documentos del ramo de Hacienda, como las Memorias anuales de sus secretarios y la correspondencia interna a la Administración de Aduanas, es importante utilizar, entre otras posibilidades, los archivos de otras dependencias del Estado y, sobre todo, la prensa nacional y regional dedicada a tópicos generales así como particulares. Lo que atañe a la política económica, en sus dimensiones arancelaria, fiscal y comercial, constituye el aspecto más fácil de documentar y sobre el cual existe ya una útil bibliografía. La cuestión se complica cuando se busca entender el funcionamiento de la Administración de Aduanas, adentrarse en el mundo de la penalización del contrabando o penetrar las mentalidades y las conductas sociales. A pesar de las dificultades, se llega a precisar la multiplicidad de trabas que enfrentaba el Estado para hacer respetar su legislación e impedir la práctica del contrabando. Se sumaron los elementos que permiten explicar por qué el comercio ilícito no desapareció y más bien continuó siendo un fenómeno difundido, puesto que, en los cuatro campos abordados, los contrabandistas encontraron las fallas que hicieron posible su permanencia en el tiempo. Asimismo, es posible percibir el arraigo social y cultural de las actividades ilícitas que en últimas no lo eran desde el punto de vista de los involucrados.

12. Manuel María Madiedo, "Literatura. Monopolio del tabaco", El Neo-Granadino, núm. 1, 4 de agosto de 1848, pp. 4-6. El mismo texto fue publicado posteriormente como Madiedo,
"Contrabandista", 1973. 
AGN Archivo General de la Nación, Bogotá. Biblioteca Nacional, Bogotá.

Hemerografía

Anales del Municipio, Barbacoas, Colombia.

Cambio, Bogotá, Colombia.

Constitucional de Cartagena, Cartagena, Colombia.

Constitucional de Popayán, Popayán, Colombia.

Constitucional del Cauca, Popayán, Colombia.

Constitucional del Chocó, Quibdo, Colombia.

Constitucional del Magdalena, Cartagena, Colombia.

Crónica del Choco, Quibdo, Colombia.

Eco del Atrato, Quibdo, Colombia.

El Atratense, Quibdo, Colombia.

El Amigo del País, Santa Marta, Colombia.

El Amigo del Pais, Medellín, Colombia.

El Antioqueño Constitucional, Medellín, Colombia.

El Comercio. Boletín Industrial. Órgano del Comercio y de la Industria de Colombia y Oficial de la Junta de Comercio, Bogotá, Colombia.

El Constitucional Antioqueño, Rionegro, Colombia.

El Día, Bogotá, Colombia.

El Eco de la Juventud, Riohacha, Colombia.

El Economista. Órgano de la Cámara de Comercio, Bogotá, Colombia.

El Espectador, Bogotá, Colombia.

El Honor Ultrajado pero No Manchado, Barbacoas, Colombia.

El Indigena Chocoano, Quibdo, Colombia.

El Lucero de Calamar, Mompox, Colombia.

El Momposino, Mompox, Colombia.

El Neogranadino, Bogotá, Colombia.

El Neo-Granadino, Bogotá, Colombia.

El Porvenir. Periodico de la Juventud, Cartagena, Colombia

El Promotor, Barranquilla, Colombia.

El Promotor. Órgano de los Intereses Comerciales de Barranquilla, Barranquilla, Colombia.

El Pueblo, Santa Marta, Colombia.

El Riohachero, Riohacha, Colombia.

El Semanario Comercial, Barranquilla, Colombia.

Gaceta de Cartagena, Cartagena, Colombia.

Gaceta de Cartagena de Colombia, Cartagena, Colombia 
Gaceta de Colombia, Bogotá, Colombia.

Gaceta de la Nueva Granada, Bogotá, Colombia.

Gaceta del Cauca, Popayán, Colombia.

La Bandera Nacional, Bogotá, Colombia.

La Época, Bogotá, Colombia.

La Gaceta Mercantil, Santa Marta, Colombia

La Situación, Santa Marta, Colombia.

La Voz del Comercio, Cartagena, Colombia.

Mercurio del Consulado de Cartagena, Cartagena, Colombia.

Registro Oficial de Hacienda, Bogotá, Colombia.

Repertorio Judicial, Bogotá, Colombia.

Repertorio Judicial de la Nueva Granada, Bogotá, Colombia.

Semana, Bogotá, Colombia.

BIBLIOGRAFIA

Al mundo. Testamento del señor don Silvestre Cotes, alias El Adelantado (Riohacha, 10 de octubre de 1834). Se publica adornado de sus respectivos epitafios en honor a tan distinguido caballero, Cartagena, impreso por Manuel María Guerrero, 1834, 5 pp. (Rubricado en la biblioteca Luis Ángel Arango como "La Guajira, el mamagallismo y el contrabando").

AraUz, Celestino, El contrabando holandés en el Caribe durante la primera mitad del $S$. XVIII, Caracas, Academia Nacional de Historia, 1984, 2 tt.

Barrera, Edunddo, Mestizaje, comercio y resistencia. La Guajira durante la segunda mitad del siglo XVIII, Bogotá, Instituto Colombiano de Antropología e Historia, 2000 (Cuadernos de Historia Colonial, título vi).

Bernecker, Walther, Contrabando. Ilegalidad y corrupción en el México del siglo XIX, México, Departamento de Historia-Universidad Iberoamericana, 1994.

BushnELL, DAvid, El régimen de Santander en la Gran Colombia, Bogotá, Tercer Mundo Editores/Facultad de Sociología-Universidad Nacional, 1966 (1a. edición en inglés 1954).

, "Dos etapas de la política arancelaria colombiana: la era radical y el regreso a la protección (1861-1885)" en Jesús ANTONio BEjarano (ed.), El siglo XIX en Colombia visto por historiadores norteamericanos, Bogotá, Ed. La Carreta, 1977, pp. 82-114.

Camacho Roldán, Salvador, Memoria que el secretario de Hacienda y Fomento presenta al presidente de la república sobre el curso que han tenido los negocios fiscales de Colombia en el año económico de 1869 a 1870, Bogotá, Imprenta de Gaitán, 1871.

Codificación nacional de todas las leyes de Colombia desde el año de 1821, Bogotá, Imprenta Nacional, vol. 2, 1825-1826, vol. 3 (1827-1828).

CuencA, TOMÁs, Memoria que el secretario de Hacienda y Fomento de la Unión colombiana presenta al Congreso nacional en 1865, Bogotá, Imprenta de "El Mosaico", 1866. 
DeAs, MaLColm, "Los problemas fiscales en Colombia durante el siglo XIX" en Del poder y la gramática y otros ensayos sobre historia, política y literatura colombiana, Bogotá, Tercer Mundo Editores, 1993, pp. 61-120.

GALINDO, ANíBAL, Historia económica y estadística de la Hacienda nacional, desde la colonia hasta nuestros días, Bogotá, Imprenta de Nicolás Pontón, 1874.

, Memoria del secretario de Hacienda dirigida al presidente de la Unión para el Congreso de 7884, Bogotá, Imprenta a cargo de N. Torres, 1885.

GRAHN, LANCE RAYMOND, The Political Economy of Smuggling, Regional Informal Economies in Early Bourbon New Granada, Nueva York, Westview Press, 1997 (Dellplain Latin American Studies, 35)

Jaramillo, Jaime, Adolfo Meisel y Miguel Urrutta, Continuities and Discontinuities in the Fiscal and Monetary Institutions of New Granada 1783-1850, Bogotá, Banco de la República, 1997 (Borradores Semanales de Economía, 74).

López, Luis Fernando, Historia de la Hacienda y el Tesoro en Colombia, 1821-1900, Bogotá, Banco de la República, 1992 (Historia y Teoría Económica).

Madiedo, MANUel Marfa, "El contrabandista" en Museo de cuadros de costumbres. Variedades y viajes. Biblioteca de 'El Mosaico', 1866, Bogotá, Biblioteca Banco Popular, 1973, vol. 46, t. 1, pp. 309-320.

MaYo, John, "Consuls and Silver Contraband on Mexico's West Coast in the Era of Santa Anna", Journal of Latin American Studies, vol. 19, núm. 2, 1987, pp. 389-411.

MELO, JoRge ORLANDo, "Las vicisitudes del modelo liberal (1850-1899)" en J. A OCAMPO (comp.), Historia económica de Colombia, Bogotá, Siglo XXI Editores/ FEDesarRollo, 1987, p. 119-172.

MORENO, ABRAHAM, Informe que el secretario de Hacienda presenta al ciudadano gobernador del Estado de Antioquia Medellín. Imprenta de Isidoro Isaza, 10 de julio de 1867.

MúnerA, Alfonso, El fracaso de la nación. Región, clase y razas en el Caribe colombiano (1717-1810), Bogotá, Banco de la República/El Áncora Editores, 1998.

"Ilegalidad y frontera, 1700-1800" en A. MEISEL (ed.), Historia economica y social del Caribe colombiano, Bogotá, Ed. Uninorte, 1994, pp. 109-154.

Nieto, Luis EduARdo, Economía y cultura en la historia de Colombia, Bogotá, Banco de la República/El Áncora Editores, 1942.

OCAMPO, JOSÉ ANTONIO, "Librecambio y proteccionismo en el siglo XIX" en J. A. OCAMPO y S. MONTENEGRO, Crisis mundial, protección e industrialización. Ensayos de historia económica, Bogotá, Fondo Editorial CEREC, 1984, pp. 235-295.

Palacios, Marco y Frank Robinson Safrord, Colombia. País fragmentado, sociedad dividida. Su historia, Bogotá, Norma, 2002 (Vitral).

PARsons, JAMEs, Urabá, salida de Antioquia al mar. Geografia e historia de su colonización, Bogotá, Banco de la República/El Áncora Editores, 1996.

Parra, AQUileo, Memoria del secretario de Hacienda i Fomento dirigida al presidente de la república para el Congreso de 1873, Bogotá, Imprenta de Gaitán, 1874.

PETTT, RoBERT L., Dictionnaire alphabétique et analogique de la langue française, París, Dictionnaires le Robert, 1986. 
POLO, JosE, "Contrabando y pacificación indígena en una frontera del Caribe colombiano: La Guajira (1759-1800)", Aguaita. Revista del Observatorio del Caribe Colombiano, núm. 3, junio de 2000, Cartagena, pp. 41-62.

RoldÁn, ANTONio, Memoria del secretario de Hacienda dirigida al presidente de la Unión para el Congreso de 1882, Bogotá, Imprenta a cargo de H. Andrade, 1883.

SAFFORD, FRANK, "Comercio y empresa en Colombia central 1821-1870", tesis de doctorado, 1965 (traducción de J. P. Martínez, 2000).

SAMPER, MiguEL, Memoria del secretario de Hacienda y Fomento al ciudadano presidente de la Unión para el Congreso federal de 1869, Bogotá, Imprenta de la Nación, 1870.

TOVAR, HERMES, "La lenta ruptura con el pasado colonial (1810-1850)" en J. A. OCAMPO (comp.), Historia económica de Colombia, Bogotá, Siglo XXI Editores/FEDESARROLLO, 1987, pp. 87-117.

VIDAL, ANTONINo, Cartagena de Indias y la región histórica del Caribe, 1580-1640, Sevilla, Consejo Superior de Investigación Científica-Escuela de Estudios HispanoAmericanos-Universidad de Sevilla/Diputación de Sevilla, 2002. 